\section{Light acclimation of leaf gas exchange in two Tunisian cork oak populations from contrasting environmental conditions}

\author{
Touhami Rzigui $^{(1)}$, Habiba Khiari ${ }^{(1)}$, Zouhaier Abbes ${ }^{(2)}$, Khaoula Ben \\ Baaziz $^{(1)}$, Ichrak Jaouadi ${ }^{(3)}$, Zouheir Nasr ${ }^{(1)}$
}

Due to diverse environmental conditions, Mediterranean plant populations are exposed to a range of selective pressures that may lead to phenotypic plasticity and local adaptation. We examined the effect of light acclimation on photosynthetic capacity in two Quercus suber (L.) populations that are native to different ecological conditions. Low-light adapted seedlings from both populations were exposed to three light treatments: full sunlight $(\mathrm{HL})$, medium light (ML, 43\% sunlight) and low light (LL, 15\% sunlight) for one month. Photosynthetic performance was monitored by measuring leaf gas exchange and chlorophyll fluorescence parameters. The light environment influences light-saturated carbon assimilation $\left(A_{\max }\right)$ in the leaves of the population inhabiting the hot and dry region (from Gaafour). In contrast, there was no significant difference in $A_{\max }$ between leaves grown in high light and low light from Feija (the population native to a cold and humid climate), which suggests an inability of the Feija population to adjust its photosynthesis to respond to higher irradiance. The inability of the Feija population to adjust its photosynthesis did not result from a light acclimation failure in terms of chlorophyll content and ratio compared with the Gaafour population. Instead, it seems to be the consequence of lower stomatal conductance in the Feija population at $\mathrm{HL}$ compared to Gaafour.

Keywords: Quercus Suber L., Photosynthesis, Stomatal Conductance, Light, Acclimation

\section{Introduction}

Light is one of the most heterogeneous factors affecting plant growth and development, though plants are well-adapted to seasonal and diurnal light fluctuations (Gomez-Aparicio et al. 2006). High light can be considered to be a stress factor in Mediterranean ecosystems.

Forest tree species are distributed across a wide range of environmental conditions and subjected to different selective pressures (Ramirez-Valiente et al. 2010). Long-term selection can lead to the development of morphological and physiological adaptations to the local environment, giving rise to ecotypic differentiation (Blaguer et al. 2001, Magri et al. 2006, 2007). Plant species can cope with this environmental variability by enhancing phenotypic plasticity and adapting to local climates (Sultan 2003).

Cork oak (Quercus suber L.) is a sclerophyllous, evergreen Mediterranean tree species adapted to long dry summer conditions with little or no precipitation, maximum temperatures reaching $35-40^{\circ} \mathrm{C}$, and irradiance exceeding $2000 \mu \mathrm{mol} \mathrm{m}^{-2} \mathrm{~s}^{-1}$ (PAR) at midday. Such high irradiance can inhibit net carbon uptake, especially in sun-exposed leaves

(1) National Research Institute for Rural Engineering, Waters, and Forestry, Box 10, Ariana 2080 (Tunisia); (2) Field Crop Laboratory, Carthage University, National Institute for Agricultural Research of Tunisia (INRAT), Rue Hédi Karray, 2080 Ariana (Tunisia); (3) EL Manar University, Faculty of Science, Department of Biology, Tunis (Tunisia)

(a) Touhami Rzigui (rziguitouhami@gmail.com)

Received: Apr 03, 2014 - Accepted: Sep 04, 2014

Citation: Rzigui T, Khiari H, Abbes Z, Baaziz KB, Jaouadi I, Nasr Z, 2015. Light acclimation of leaf gas exchange in two Tunisian cork oak populations from contrasting environmental conditions. iForest 8: 700-706 [online 2015-01-08] URL: http://www.sisef.it/iforest/ contents/?id=ifor1306-007

Communicated by: Silvano Fares

(Faria et al. 1996). Sun leaves are thicker, and their chloroplasts are smaller with lower concentrations of total chlorophyll in comparison with shade leaves. These differences between sun and shade leaves can be readily observed in many species or when a single species is grown under different light intensities (Boardman 1977). Walters (2005) observed that acclimation to high light intensity increases maximum photosynthetic rate, while Price et al. (1998) suggested that the marked changes in the cytochrome $b / f$ complex can be linked to changes in photosynthetic capacity. Since the 1980 's, it has been thought that the acclimation of plants to their environment is generally dictated by strategies aimed at maximizing the photosynthetic rate (Ort 2001). The factors influencing the photosynthetic rate in both sun and shade plants have been reported by Boardman (1977) and Ort (2001). In addition to increasing the efficiency of light absorption and primary photosynthetic reactions, the maximum photosynthetic capacity could be influenced by stomatal and mesophyll resistance to $\mathrm{CO}_{2}$ diffusion (Flexas \& Medrano 2002, Rzigui et al. 2013). Furthermore, it has been reported that sun-adapted species show stomatal and mesophyll conductance much higher than shade-adapted species grown under identical conditions with artificial light (Holmgren 1968) and throughout the seasons (Mendes et al. 2001). It is likely that $\mathrm{CO}_{2}$ diffusion is a crucial factor in the photosynthetic differences between shade and sun species.

In this study, we investigated whether habitat of origin has any effect on photosynthetic acclimation to light. For this purpose, we examined the ability to adjust carbon assimilation in response to higher growth irradiance in cork oak (Quercus suber L.) seedlings originating from two Tunisian populations representing a marked climate gradient.

\section{Materials and Methods}

\section{Seed origin and experimental design}

In October 2010, Q. suber L. acorns were collected from two populations originating from contrasting environments in the northwestern provinces of Tunisia (Tab. 1). The first site, the National Park of Feija (36 $30^{\prime}$ $00^{\prime \prime} \mathrm{N}, 8^{\circ} 20^{\prime} 00^{\prime \prime} \mathrm{E}$ ), is located in the northern extent of the Kroumirie Mountains and is characterized by a cold and humid climate. The average temperature is $7{ }^{\circ} \mathrm{C}$ in January and can drop to $0^{\circ} \mathrm{C}$, which allows for yearround snowfall. The second site is located at Gaafour (36 32' 19" N, 9० 32' 40" E) in the southern hills and plains around Siliana, and it is characterized by a semiarid climate with moderate winters and hot dry summers. Immediately after collection, acorns were planted in the greenhouse of the National Re- 
Tab. 1 - Climatic characteristics of the seed source locations and mean seedling height $(n=$ 9) of the studied cork oak populations.

\begin{tabular}{lcccc}
\hline Provenance & Altitude (m) & $\begin{array}{c}\text { Mean annual } \\
\text { rainfall }(\mathbf{m m})\end{array}$ & $\begin{array}{c}\text { Mean annual } \\
\text { temperature }\left({ }^{\circ} \mathbf{C}\right)\end{array}$ & $\begin{array}{c}\text { Seedlings mean } \\
\text { height }(\mathbf{c m})\end{array}$ \\
\hline Feija & $550-1555$ & 1217 & 14.3 & $74.66 \pm 4.17$ \\
Gaafour & 276 & 480 & 17.6 & $68.77 \pm 1.90$ \\
\hline
\end{tabular}

search Institute for Rural Engineering, Waters, and Forestry under low light conditions (LL, 15\% of full sunlight). On October 1, 2013, low-light adapted seedlings that had been grown in $5 \mathrm{~L}$ pots containing a mixture of equal parts of soil and compost were randomly assigned to one of three light treatments for one month: (1) high light $(100 \%$

natural incident irradiance, HL); (2) medium light (43\% of full sunlight, ML); and (3) low light (LL, $15 \%$ of full sunlight). In the ML and LL treatments, light levels were obtained through the use of layers of neutral shadecloth, while seedlings were left uncovered in the HL treatment. Photosynthetically active radiation was measured (Li-190, Li-Cor Bio-

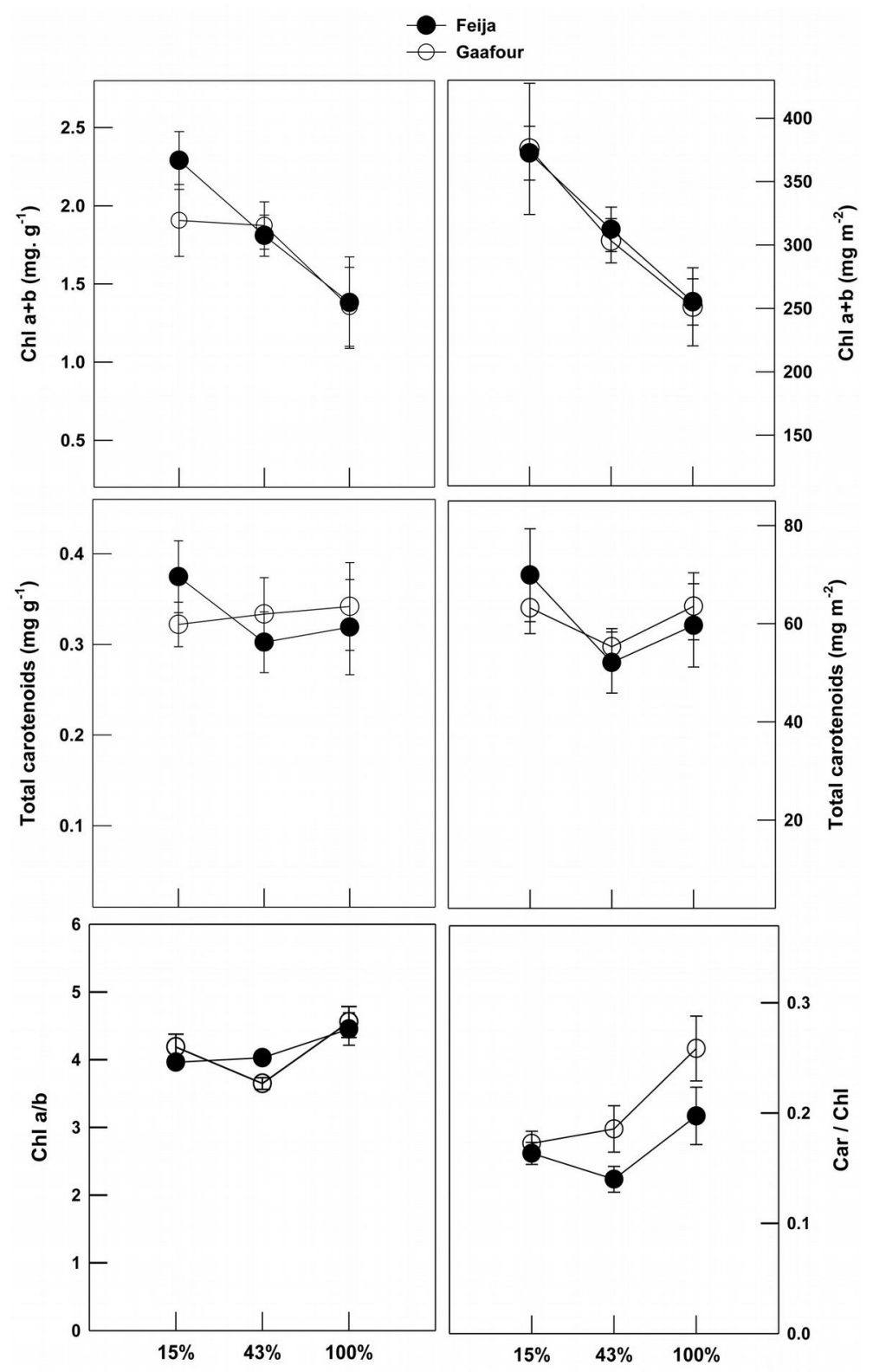

Fig. 1 - Leaf pigments content: Chl $a+b$ and total carotenoid concentrations per unit leaf area and fresh weight and chlorophyll $a / b$ and carotenoids/total chlorophyll (Car/Chl) ratios. Values shown represent the mean of at least three replicates with standard errors. science, Lincoln, NE) at midday on October 23, 2013, and it ranged between 1630-1810 $\mu \mathrm{mol} \mathrm{m} \mathrm{m}^{-2} \mathrm{~s}^{-1}$ 634-766 $\mu \mathrm{mol} \mathrm{m} \mathrm{m}^{-2} \mathrm{~s}^{-1}$ and 215$315 \mu \mathrm{mol} \mathrm{m}^{-2} \mathrm{~s}^{-1}$ in the HL, ML and LL treatments, respectively. Differences in maximum and minimum daily temperatures between treatments did not exceed $4^{\circ} \mathrm{C}$ (data not shown). Irrigation to saturation was provided manually each day. To ensure homogeneity of soil humidity between light treatments and provenances during the experiment, soil water content was monitored weekly by time domain refractometry (TDR, Trase system I, Soil moisture Equipment Corp., USA) in a subsample of pots. Mean volumetric soil water content of the pots containing seedlings in all three light treatments was approximately $25-30 \%$. Each block containing 20 seedlings per light treatment was periodically moved to minimize the possible effects of within-block light variability. All experiments were carried out on fully expanded, mature leaves that had developed before the light treatment.

\section{Gas exchange measurements}

The photosynthetic response of the leaves to varying levels of photosynthetic photons flux density $(P P F D)$ was measured at the ambient $\mathrm{CO}_{2}$ concentration $(400 \mathrm{ppm})$ with an open infrared gas analysis system (Li-Cor 6400-40 equipped with a red-blue LED source; Li-Cor Inc., Lincoln, NE, USA). Light response curves were measured for attached leaves at $25{ }^{\circ} \mathrm{C}$ at an airflow rate of $300 \mathrm{~cm}^{3} \mathrm{~min}^{-1}$. The vapor pressure deficit was kept at $1.2 \pm 0.2 \mathrm{kPa}$. Each cork oak leaf was allowed to reach a steady state at an incident light level of $1200 \mu \mathrm{mol} \mathrm{m} \mathrm{m}^{-2} \mathrm{~s}^{-1}$ PAR. We then changed the $P P F D$, and net photosynthesis $\left(A_{\mathrm{n}}\right)$ was recorded at each $P P F D$ level once it became stable. Stomatal conductance $\left(g_{s}\right)$ and transpiration $(E)$ were also recorded concurrently. Instantaneous wateruse-efficiency ( $W U E$ ) was calculated as $A_{\mathrm{n}} / E$ $\left(\mu \mathrm{mol} \mathrm{CO} \mathrm{Cmol}^{-1} \mathrm{H}_{2} \mathrm{O}\right)$. Photosynthetic capacity was estimated by light-saturated net photosynthetic rate $\left(A_{\max }\right)$ as determined by fitting $A_{\mathrm{n}} / P P F D$ curves using a three component exponential function (see Meng et al. 2014 - eqn. 1):

$$
A_{n}=A_{\max }\left(1-e^{-b * P A R}\right)+c
$$

where $A_{\mathrm{n}}$ is the net photosynthetic rate, and $A_{\max }$ is the maximum photosynthetic rate. For each light curve, the apparent quantum yield on the basis of incident light $(\Phi)$ was calculated as the initial slope at the 3 lowest $P P F D$ values (between 0 and $100 \mu \mathrm{mol} \mathrm{m} \mathrm{m}^{-2}$ $\left.\mathrm{s}^{-1}\right)$. The light compensation point $(L C P)$ was estimated from the $\mathrm{x}$-axis intercepts.

\section{Chl fluorescence measurements}

In vivo chlorophyll a fluorescence emissions in 30-min dark-adapted leaves were 
measured with a portable modulated chlorophyll fluorometer (Opti-Sciences, OS-30p+) at predawn and midday. After adaptation to the dark, the modulated fluorometer allows the accurate measurement of minimum fluorescence $\left(F_{\mathrm{o}}\right)$ using a weak, modulated light that is too low to induce photosynthesis. In this state, photosystem II is maximally oxidized. A subsequent saturating flash of white light $(3500 \mu$ mols $)$ reduces all available PSII reaction centers, and the maximum fluorescence $\left(F_{\mathrm{m}}\right)$ during the saturating light radiation is recorded. The maximum photochemical efficiency of PSII was calculated as the ratio of the light-induced variable and the maximum fluorescence of chlorophyll, $F_{\mathrm{v}} / F_{\mathrm{m}}$ (eqn. 2):

$$
\frac{F_{v}}{F_{m}}=\frac{\left(F_{m}-F_{o}\right)}{F_{m}}
$$

\section{Photosynthetic pigments}

The same leaves used for the measurement of gas exchange were sampled for the assessment of the total content of chlorophyll and carotenoids. Leaf tissue of known area (measured using a leaf area meter, Portable Laser, Model Cl-202) and fresh weight was incubated in $80 \%$ acetone until all of the chlorophyll was visibly extracted. Spectrophotometer readings of the extracts were obtained at $750,663,645$ and $453 \mathrm{~nm}$ to determine the chlorophyll $a$ and $b$ and total carotenoid contents using the equations of Arnon (1949). Chlorophyll and carotenoid concentrations were estimated on the basis of fresh weight and leaf area.

All experiments were repeated at least 3 times, and the mean values and standard errors of the data are shown. Statistically significant differences at the 5\% level were calculated with the Student's $t$-test using the software package SigmaPlot ${ }^{\circledR}$ (Systat Software Inc., San José, CA, USA).

\section{Results}

\section{Photosynthetic pigments}

Total chlorophyll concentration on the basis of fresh mass basis and leaf area declined significantly as growth irradiance increased for both populations (Fig. 1). The area and

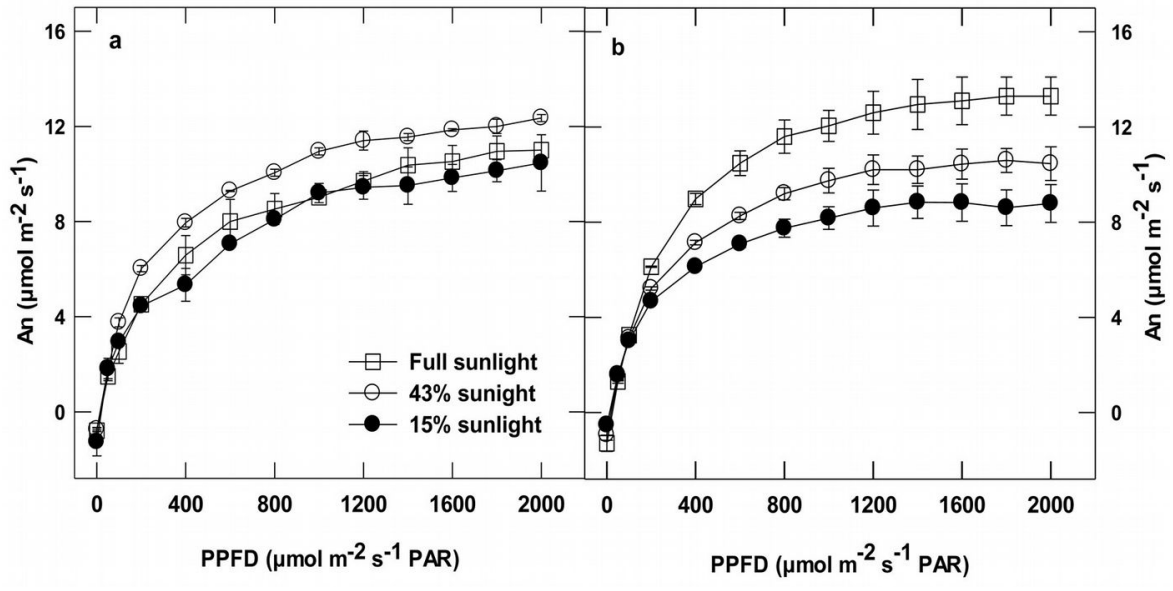

Fig. 2 - Light response curves: Net carbon assimilation $\left(A_{\mathrm{n}}\right)$ of attached leaves measured at different PPFD levels in an atmosphere of $400 \mathrm{ppm} \mathrm{CO}_{2}$ and $25^{\circ} \mathrm{C}$ from Feija (a) and Gaafour (b). Values are means $\pm \mathrm{SE}$ of at least three independent measurements.

mass-based carotenoid concentrations were not affected by the different light treatments for either provenance. The ratio of chlorophyll $a / b$ remained unchanged at different light treatments in the Feija population, but it decreased in Gaafour leaves at $43 \%$ sunlight. The $\mathrm{Car} / \mathrm{Chl}$ ratio did not vary with increasing light in the Feija populations. In contrast, there was a significant increase in the $\mathrm{Car} / \mathrm{Chl}$ ratio in HL in the Gaafour population.

\section{Photosynthetic response to growth under different light levels}

Photosynthesis light curves showed a marked acclimation response to the growth irradiance in the Gaafour but not in the Feija leaves (Fig. 2). Net carbon uptake in the Gaafour leaves at full sunlight was higher than in those grown at LL and ML, light intensities $\geq 200 \mu \mathrm{mol} \mathrm{m}^{-2} \mathrm{~s}^{-1}$ PAR. There was no significant change in the light compensation point $(L C P)$ in the Feija leaves (Tab. 2). In the Gaafour leaves, $L C P$ increased proportionally to the intensity of the growth light. Apparent quantum yield $(\Phi)$ only increased for HL-grown plants of Gaafour provenance compared to the counterparts grown in low light (Tab. 2). In contrast, the apparent quantum yield increased at ML only in plants of Feija provenance in comparison with plants grown at LL. Furthermore, maximum applied $P P F D$ completely saturated photosynthesis only in the Gaafour population under LL and ML conditions. As shown in Fig. 2, net photosynthesis rate $\left(A_{\mathrm{n}}\right)$ was higher in Feija than Gaafour leaves grown at low and medium light but significantly lower when grown at high light. This suggests that the capacity to acclimate to high light was different between provenances because the assimilation rate across light regimes only increased in Gaafour seedlings.

In summary, net carbon assimilation was comparable in Feija leaves grown under both low and high light conditions, which suggests that there was no stimulation of $A_{\mathrm{n}}$ at HL compared to LL. Obviously, the Gaafour population is able to acclimate its photosynthetic activity to high light whereas the Feija plants cannot.

\section{Variations of $g_{s}, E$ and WUE in response to light}

Stomatal conductance $\left(g_{\mathrm{s}}\right)$ and transpiration $(E)$ changed similarly as PPFD increased in plants of both Feija and Gaafour provenance. Under full sunlight, $g_{s}$ and $E$ increased in Gaafour plants compared with those grown under low and medium light (Fig. 3). For the

Tab. 2 - Light-saturated photosynthesis $\left(A_{\max }\right)$, light compensation point $(L C P)$ and apparent quantum yield $(\Phi)$ in leaves of Gaafour and Feija provenances grown under three light regimes. Different uppercase letters indicate a significant difference between provenances in the same light environment, whereas lowercase letters indicate significant differences between light environments in the same provenance ( $\mathrm{p} \leq$ 0.05 , Student's $t$-test).

\begin{tabular}{|c|c|c|c|c|c|c|}
\hline \multirow{2}{*}{ Parameter } & \multicolumn{3}{|c|}{ Feija } & \multicolumn{3}{|c|}{ Gaafour } \\
\hline & LL (15\%) & ML (43\%) & HL (100\%) & LL (15\%) & ML (43\%) & HL $(100 \%)$ \\
\hline $\begin{array}{l}A_{\max } \\
\left(\mu \mathrm{mol} \mathrm{CO}{ }_{2} \mathrm{~m}^{-2} \mathrm{~s}^{-1}\right)\end{array}$ & $10.36 \pm 0.8^{\mathrm{Aa}}$ & $11.92 \pm 0.27^{\mathrm{Ab}}$ & $11.20 \pm 0.29^{\mathrm{Aa}}$ & $8.84 \pm 0.77^{\mathrm{Aa}}$ & $10.45 \pm 0.71^{\mathrm{Ba}}$ & $13.30 \pm 1.10^{\mathrm{Bb}}$ \\
\hline $\begin{array}{l}L C P \\
\left(\mu \mathrm{mol} \text { photons } \mathrm{m}^{-2} \mathrm{~s}^{-1}\right)\end{array}$ & $19.30 \pm 2.00^{\mathrm{Aa}}$ & $14.60 \pm 1.60^{\mathrm{Aa}}$ & $19.60 \pm 2.00^{\mathrm{Aa}}$ & $12.33 \pm 1.40^{\mathrm{Ba}}$ & $18.30 \pm 2.60^{\mathrm{Ab}}$ & $23.30 \pm 2.30^{\mathrm{Ab}}$ \\
\hline (mol CO ${ }_{2} \mathrm{~mol}^{-1}$ photon) & $0.034 \pm 0.001$ Aa & $0.046 \pm 0.001^{\mathrm{Bb}}$ & $0.032 \pm 0.003^{\mathrm{Aa}}$ & $0.035 \pm 0.001^{\mathrm{Aa}}$ & $0.036 \pm 0.004^{\mathrm{Ba}}$ & $0.045 \pm 0.002^{\mathrm{Bb}}$ \\
\hline
\end{tabular}



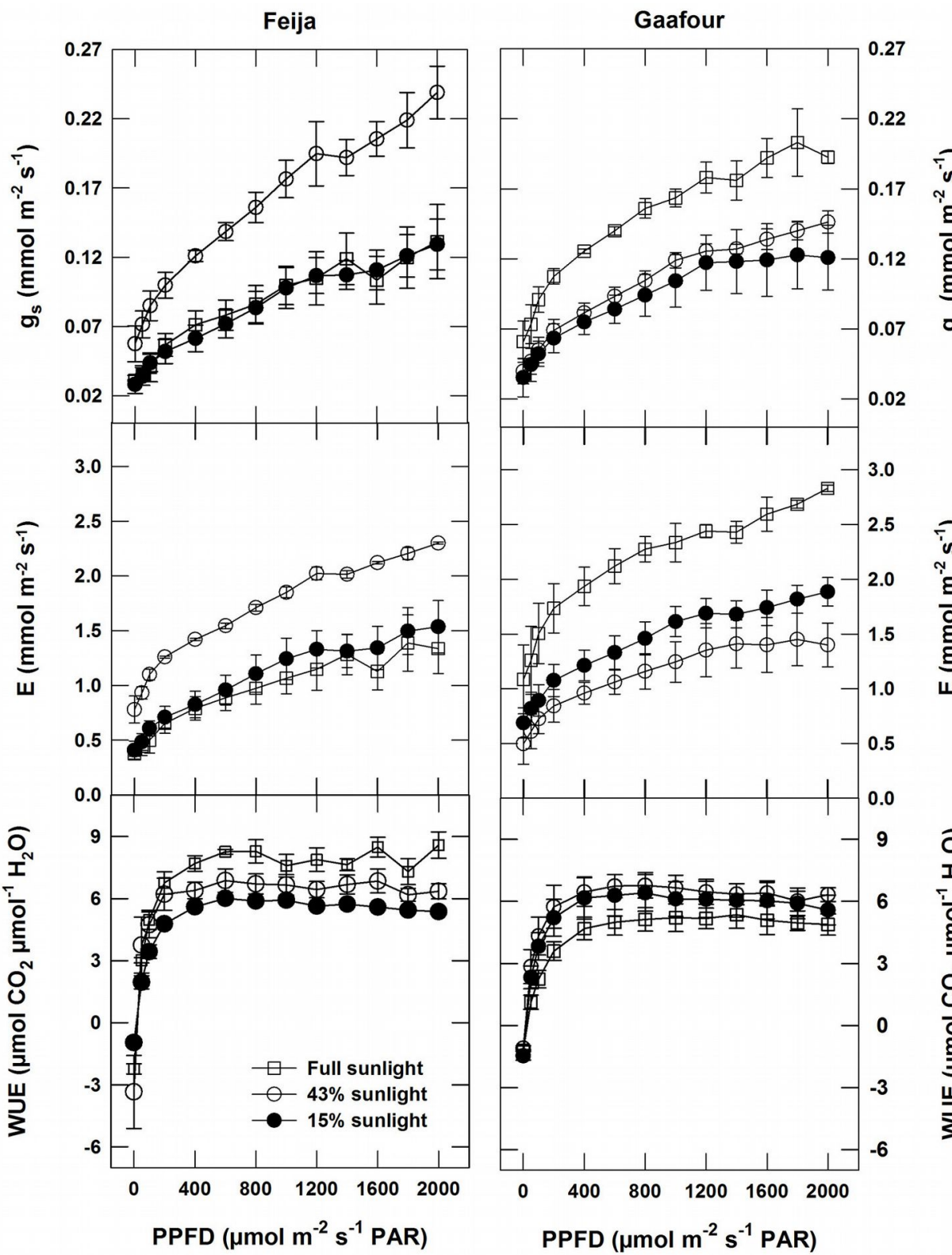

Fig. 3 - Response of gas exchange to light: Stomatal conductance $\left(g_{\mathrm{s}}\right)$, transpiration rate $(E)$ and instantaneous water use efficiency $(W U E)$ as a function of $P P F D$ in an atmosphere of $400 \mathrm{ppm} \mathrm{CO}_{2}$ and $25^{\circ} \mathrm{C}$. Values are means $\pm \mathrm{SE}$ of at least three independent measurements.

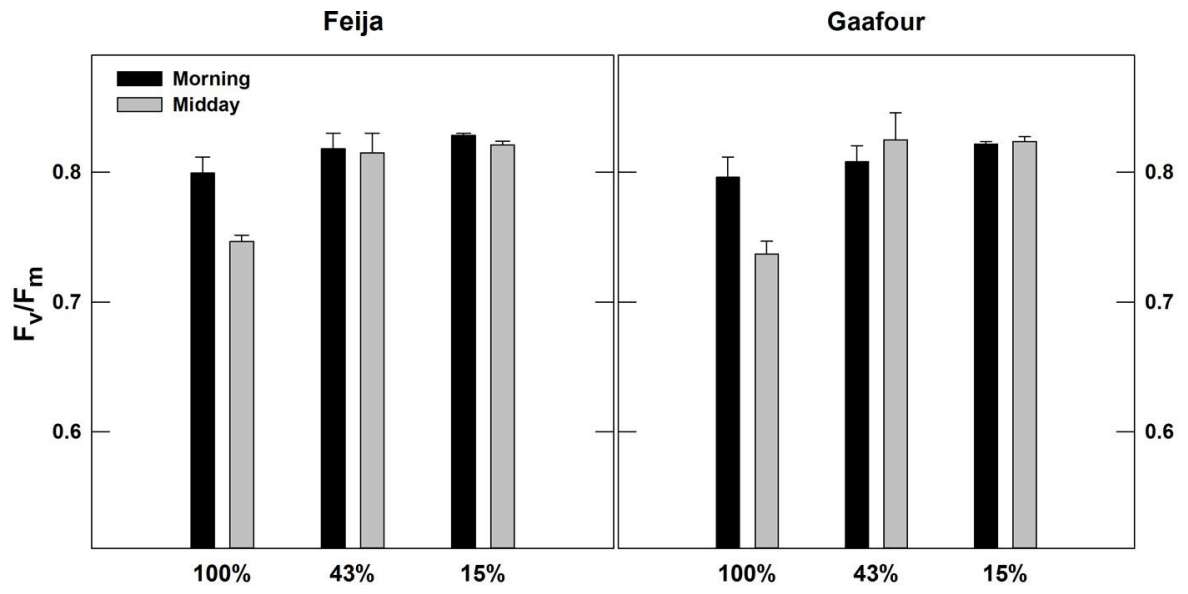

Fig. 4 - Chlorophyll fluorescence: maximal photochemical efficiency of PSII $\left(F_{\mathrm{v}} / F_{\mathrm{m}}\right)$ measured in the morning (07:00) and at midday (12:00). Values are means $\pm \mathrm{SE}$ of five independent measurements.
Feija plants, the conductance and transpiration curves of leaves grown in medium light (with the highest carbon assimilation) were above the curves of the low- and high-light leaves (Fig. 3).

Intrinsic water use efficiency (WUE) was calculated from the gas exchange measurements. For the three light treatments, WUE was completely saturated at low light intensities $\left(<400 \mu \mathrm{mol} \mathrm{m}^{-2} \mathrm{~s}^{-1}\right)$ in both Feija and Gaafour plants. A remarkable increase in WUE in full sunlight was detected in the Feija population (Fig. 3), but there was a slight decrease in the Gaafour group (Fig. 3). Plants of both Gaafour and Feija provenance had the same WUE under LL and ML conditions.

Chl fluorescence

The diurnal evolution of the maximum 
photochemical efficiency of PSII (given by $F_{\mathrm{v}} / F_{\mathrm{m}}$ in dark-adapted leaves) is shown in Fig. 4 . The $F_{\mathrm{v}} / F_{\mathrm{m}}$ ratio remained constant at approximately 0.8 in LL and ML in both Feija and Gaafour leaves. The growth in HL decreased $F_{\mathrm{v}} / F_{\mathrm{m}}$ significantly $(\mathrm{p}<0.05)$ by 7.6 and $8.4 \%$ at midday in the plants of Feija and Gaafour provenance, respectively.

\section{Discussion}

\section{Intraspecific differences in response to high light}

This study shows that the sensitivity of photosynthetic capacity to light availability was distinguishable between two populations belonging to different natural habitats. The Feija population was the least tolerant to HL, exhibiting severe restrictions to gas exchange and performance of photosynthesis The plants of Gaafour provenance were the most tolerant to the high levels of irradiance but showed low photosynthetic capacity when treated with medium and low light. In terspecific differences in acclimation to HL among Mediterranean species have been studied previously (Kolber et al. 1988, Hugh et al. 2002, Valladares et al. 2002, 2004, Gomez-Aparicio et al. 2006, Sanchez-Gomez et al. 2006, Rozendal et al. 2006). It has been suggested that species acclimate to full sunlight conditions by increasing their photosynthetic capacity (Marenco et al. 2001) However, interpopulation differences in the response to the light environment have been analyzed less frequently. In cork oak, some studies have investigated the possible existence of intraspecific variability as an adaptation to contrasting regional climate conditions. For example, Staudt et al. (2008) examined intraspecific variability in the emission of volatile organic compounds during drought in Tunisian cork oak populations originating from contrasting climatic conditions. More recently, Ramirez-Valiente et al (2010) tested the phenotypic plasticity of 13 contrasting European cork oak populations under conditions of differential water availability. Additionally, the interpopulation variability in temperature response was investigated for other cork oak populations (Aranda et al. 2005). The results found in this study show that the ecological origin of the populations determined their capacity for light acclimation. Blaguer et al. (2001) also found that populations of $Q$. coccifera, an evergreen oak originating from different localities in the Mediterranean, differ in their plastic response to light intensity. They concluded that differences among populations suggested an ecotypic differentiation towards less phenotypic plasticity in the most homogeneous light environments (Blaguer et al. 2001). More recently, Aranda et al. (2005) found differences in cold tolerance among populations of cork oak. Our findings indi- cate a divergence in the plasticity of $Q . s u$ ber populations in response to the light environment. In this species, a change in plasticity may be a consequence of habitat-based selection, as proposed by Blaguer et al. (2001).

\section{Light acclimation of chlorophyll content and ratio}

Light acclimation is commonly associated with an increase in the $\mathrm{Chl} a / b$ ratio (Anderson \& Osmond 1987), which reflects a relatively lower ratio of light harvesting complexes (LHCs) to reaction centers (Priault et al. 2006). However, in our study, the Chl $a / b$ ratio was not significantly affected by high light treatment in plants of either provenance (Fig. 1). This result is in accordance with several studies of other species that suggest that the $\mathrm{Chl} a / b$ ratio presents low plasticity in response to light (Valladares et al. 2000, Mendes et al. 2001). In contrast, GomezAparicio et al. (2006), who studied the light response of several Mediterranean tree saplings, showed that area- and mass-based carotenoid concentrations and $\mathrm{Chl} a / b$ ratio increased with increasing light intensity. In shade leaves, the increased Chl concentration has been interpreted as an adjustment to low light regimes (Mendes et al. 2001, Dai et al. 2009). This marked decrease in total chlorophyll content with increasing light was shown on both area and dry mass basis by Valladares et al. (2000) in two other oak species (Quercus ilex and Q. coccifera). We suggest that the inability of the Feija population to adjust its rate of photosynthetic carbon assimilation to higher growth irradiance was not related to lower light acclimation of the chlorophyll content; it seems to be linked to other factors.

\section{Apparent quantum yield and maximum photochemical efficiency of PSII}

The maximum photochemical efficiency of PSII (given by $F_{\mathrm{v}} / F_{\mathrm{m}}$ in dark-adapted leaves) in leaves grown in low and medium light remained constant during the day in both populations. However, it decreased slightly but significantly $(\mathrm{p}<0.05)$ at the midday depression in leaves grown in full sunlight (Fig. 4). It was demonstrated that $F_{\mathrm{v}} / F_{\mathrm{m}}$ of cork oak sun leaves exhibited a slight, reversible midday depression that co-occurred with the increase of light and temperature (Faria et al. 1996). This slight reduction in the midday $F_{\mathrm{v}} / F_{\mathrm{m}}$ in seedlings of both populations exposed to high light may be due to the light-induced downregulation of PSII (Müller et al. 2001, Mishra et al. 2012). Faria et al. (1996) showed that $Q$. suber leaves have the ability to dissipate excessive light energy at midday through a non-photochemical mechanism. Cork oak, a widely distributed forest tree species in the Mediterranean basin, is not well adapted to low temperatures, and a lar- ge decline in $F_{\mathrm{v}} / F_{\mathrm{m}}$ in populations originating from warmer sites was observed (Aranda et al. 2005). However, the species is able to maintain maximum photochemical efficiency of PSII during periods of drought (Faria et al. 1998). Additionally, Ghouil et al. (2003) demonstrated its tolerance to high temperatures.

The highest maximum photosynthetic rates and apparent quantum yields in Feija plants were achieved under the ML condition (Tab. 2). However, plants of Gaafour provenance acclimate better to the HL condition. The apparent quantum yield reflects "photochemical efficiency" (Hall 1979), which means that under the HL condition, 31 and 22 photons are required for the assimilation of one molecule of $\mathrm{CO}_{2}$, in the Feija and Gaafour populations, respectively. As indicated, the lower $\Phi$ can explain the poor performance of Feija plants in comparison to Gaafour at full sunlight. Generally, light-demanding species have a higher light-saturated leaf photosynthetic rate than shade-tolerant species (Hanba et al. 2002). This observed difference in photosynthetic plasticity between the two study populations suggests a limited ability of the Feija seedlings to benefit from high light conditions.

\section{Stomatal resistance to $\mathrm{CO}_{2}$ diffusion may become limiting in leaves of Feija provenance grown in high light}

The highest stomatal conductance $\left(g_{\mathrm{s}}\right)$ values and transpiration rates $(E)$ were found in leaves grown in high light and medium light for the Gaafour and Feija populations, respectively, which correlates well with the highest $A_{\text {max }}$ recorded in both groups. This is consistent with the results of Marenco et al. (2001) who found higher $g_{\mathrm{s}}$ and $E$ in Swietenia sun leaves, suggesting that this species is more efficient than Dipteryx species in controlling water loss and $\mathrm{CO}_{2}$ uptake in open fields.

It is well known that the opening and closing of the stoma enables terrestrial plants to adjust their gas exchange (uptake of $\mathrm{CO}_{2}$ and evaporation of water) in response to environmental and physiological conditions (Schluter et al. 2003). The results of this study show that only Gaafour plants could use the additional supplied light for increased $\mathrm{CO}_{2}$ fixation under the $\mathrm{HL}$ condition, as indicated by its enhanced assimilation rates. Feija plants may dissipate more energy via nonphotochemical quenching, which would be an interesting subject for further study. For plants of this provenance, high light intensity affected the efficiency of $\mathrm{CO}_{2}$ diffusion into intercellular spaces, so the photosynthetic performance of the leaves declined. Considering the often observed, coordinated regulation of leaf hydraulic conductance ( $\left.K_{\text {leaf }}\right), g_{s}$ and photosynthetic capacity (Hubbard et al. 2001, Sack \& Holbrook 2006, Sugiura \& 
Tateno 2014) in response to the light environment, we suggest that the limitation of photosynthetic rates in the Feija plants under HL compared to the Gaafour plants can be attributed to their lower $g_{s}$. It was shown that, in the sun leaves of Myrtus communis, $\mathrm{CO}_{2}$ uptake was improved by increased stomatal density (Mendes et al. 2001). Additionally, Evans (1999) results show that, under high irradiance, the lower assimilation rate of sclerophyllous leaves was accompanied by a lower concentration of chloroplas tic $\mathrm{CO}_{2}(\mathrm{Cc})$ compared to mesophyllous leaves.

The response of WUE to the light treatments was different to the response of $A_{\mathrm{n}}$. A positive relationship was observed between WUE and growth irradiance in the population from Feija. However, the seedlings of Gaafour provenance had the lowest WUE under the HL condition, to which they were better acclimated. This result is in contrast with conclusions from previous studies suggesting that increasing WUE is an important aspect of plant acclimation to high light (Hanba et al. 2002). In species of the genus Acer, acclimation to high light can be characterized by traits that maximize $W U E$ rather than only maximizing leaf net carbon gain (Mendes et al. 2001). In our study, Gaafour seedlings grown under HL have higher $A_{\max }$ and $g_{\mathrm{s}}$, which is generally found in light-demanding species (Valladares et al. 2005, Meng et al. 2014). However, there was a trend toward higher stomatal control of water loss in HL Feija seedlings.

In conclusion, a distinct difference in photosynthetic plasticity was observed in response to the light environment between both of the studied populations. Gaafour seedlings exhibited the highest photosynthetic rate in high light, and there was a difference in carbon assimilation across light regimes that is consistent with high physiological plasticity. However, Feija seedlings were better acclimated to low and mediumlight environments. This suggests that populations originating from semi-arid sites can benefit more from high light conditions than populations from humid sites. Additional studies of more populations are necessary to corroborate this hypothesis.

\section{List of abbreviations}

$A_{\max }$, light-saturated carbon assimilation; HL, high light; LL, low light; ML, medium light; PAR, photosynthetic active radiation; $A_{\mathrm{n}}$, net photosynthesis; PPFD, photosynthetic photon flux density; LED, light emitting diode; $\mathrm{Ca}$ and $\mathrm{Ci}$, external and intercellular $\mathrm{CO}_{2}$ molar fractions, respectively; $g_{s}$, stomatal conductance; $E$, transpiration; $W U E$, water use efficiency; $L C P$, light compensation point; $\Phi$, apparent quantum yield; $F_{\mathrm{o}}$, minimum fluorescence yield; $F_{\mathrm{m}}$, maximum fluorescence yield; $F_{\mathrm{v}} / F_{\mathrm{m}}$, ratio of vari- able to maximum fluorescence called the "maximum quantum yield of PSII photochemistry"; Car, carotenoid; Chl, chlorophyll.

\section{Acknowledgments}

This work was supported by the National Research Institute for Rural Engineering, Waters, and Forestry in Tunis, Tunisia. We wish to thank Dr. Peter Streb (Université Paris-Sud 11, Ecologie, Systématique et Evolution, UMR-CNRS 8079, Orsay, France) and Dr. Kumud Bandhu Mishra (CzechGlobe - Global Change Research Center, Academy of Sciences of the Czech Republic) for carefully reading the manuscript. The constructive comments of two anonymous referees are gratefully acknowledged.

\section{References}

Anderson JM, Osmond CB (1987). Shade-sun responses: compromises between acclimation and photoinhibition. In: "Photoinhibition" (Kyle DJ, Osmond CB, Arntzen CJ eds). Elsevier, Amsterdam, The Netherlans, pp. 1-38.

Aranda I, Castro L, Alia R, Pardos JA, Gil L (2005). Low temperature during winter elicits differential responses among populations of the Mediterranean evergreen cork oak (Quercus suber). Tree Physiology 25: 1085-1090. - doi: 10.1093/treephys/25.8.1085

Arnon DI (1949). Copper enzymes in isolated chloroplasts. Polyphenoloxidase in Beta vulgaris. Plant Physiology 24: 1-15. - doi: 10.1104/pp.24.1.1

Blaguer L, Martinez-Ferri E, Pérez-Corona ME, Baquedano FJ, Castillo FJ, Manrique E (2001). Population divergence in the plasticity of the response of Quercus coccifera to the light environment. Functional Ecology 15: 124-135. - doi: 10.1046/j.1365-2435.2001.00505.x

Boardman NK (1977). Comparative photosynthesis of sun and shaded plants. Annual Review of Plant Physiology 28:355-77. - doi: 10.1146/annu rev.pp.28.060177.002035

Dai Y, Shen Z, Liu Y, Wang L, Hannaway D, Lu $H$ (2009). Effects of shade treatments on the photosynthetic capacity, chlorophyll fluorescence content of Tetrastigma hemleyanum Diels et Gilg. Environmental and experimental Botany 65: 177-182. - doi: 10.1016/j.envexpbot.2008. 12.008

Evans JR (1999). Leaf anatomy enables more equal access to light and $\mathrm{CO}_{2}$ between chloroplasts. New phytologist 143:93-104. - doi: 10.10 46/j.1469-8137.1999.00440.x

Faria T, Garcia-Plazaola JI, Abadia A, Cerasoli S, Pereira JS, Chaves MM (1996). Diurnal changes in photoprotective mechanisms in leaves of cork oak (Quercus suber) during summer. Tree Physiology 16 (1-2): 115-123. - doi: 10.1093/treephys/16.1-2.115

Faria T, Silvério D, Breia E, Cabral R, Abadia A, Abadia J, Pereira JS, Chaves MM (1998). Differences in the response of carbon assimilation to summer stress (water deficits, high light and temperature) in four Mediterranean tree species. Physiologia Plantarum 102: 419-428. - doi: 10.1034/j.1399-3054.1998.1020310.x

Flexas J, Medrano H (2002). Drought inhibition of photosynthesis in C3 plants: stomatal and non-stomatal limitations revisited. Annals of Botany 89: 183-189. - doi: 10.1093/aob/mcf027 Ghouil H, Montpied P, Epron D, Ksontini M, Hanchi B, Dreyer E (2003). Thermal optima of photosynthetic functions and thermostability of photochemistry in crok oak seedlings. Tree Physiology 23: 1031-1039. - doi: 10.1093/treephys/ 23.15.1031

Gomez-Aparicio L, Valladares F, Zamora R (2006). Differential light responses of Mediterranean tree saplings: linking ecophysiology with regeneration niche in four co-occuring species. Tree Physiology 26: 947-958. - doi: 10.1093/tree phys/26.7.947

Hall A (1979). A model of leaf photosynthesis and respiration for predicting carbon dioxide assimilation in different environments. Oecologia 143: 299-316. - doi: 10.1007/BF00344957

Hanba YT, Kogami H, Terashima I (2002). The effect of growth irradiance on leaf anatomy and photosynthesis in Acer species differing in light demand. Plant, Cell and Environment 25: 10211030. - doi: 10.1046/j.1365-3040.2002.00881.x Holmgren P (1968). Leaf factors affecting lightsaturated photosynthesis in ecotypes of Solidago virgaurea from exposed and shaded habitats. Physiologia Plantarum 21: 676-98. - doi: 10.11 11/j.1399-3054.1968.tb07293.x

Hubbard RM, Ryan MG, Stiller V, Sperry JS (2001). Stomatal conductance and photosynthesis vary linearly with plant hydraulic conductance in ponderosa pine. Plant, Cell and Environment 24: 113-121. - doi: 10.1046/j.1365-3040. 2001.00660.x

Hugh LM, Todd MK, Tracy A, Richard JG (2002). Photoacclimation of photosynthesis irradiance response curves and photosynthetic pigments in microalgae and cyanobacteria. Journal of Phycology 38: 17-38. - doi: 10.1046/j.15298817.2002.00094.x

Kolber Z, Zehr J, Falkowski P (1988). Effects of growth irradiance and nitrogen limitation on photosynthetic energy conversion in photosystem II. Plant Physiology 88: 923-929. - doi: 10.1104/ pp.88.3.923

Magri D, Vendramin GG, Comps B, Dupanloup I, Geburek T, Gömöry D, Latalowa M, Litt T, Paule L, Roure JM, Tantau I, Van Der Knaap WO, Petit RJ, De Beaulieu JL (2006). A new scenario for the Quaternary history of European beech populations: palaeobotanical evidence and genetic consequences. New Phytologist 171:199221. - doi: 10.1111/j.1469-8137.2006.01740.x Magri D, Fineschi S, Bellarosa R, Buonamici A, Sebastiani F, Scirone B, Simeone MC, Vendramini GG (2007). The distribution of Quercus suber chloroplast haplotypes matches the paleogeographical history of the western Mediterranean. Molecular Ecology 16: 5259-5266. - doi: 10.1111/j.1365-294X.2007.03587.x 
Marenco RA, Gonçalves JFC, Vieira G (2001). Leaf gas exchange and carbohydrates in tropical trees differing in successional status in two light environments in central Amazonia. Tree Physiology 21 (18): 1311-1318. - doi: 10.1093/treephys /21.18.1311

Mendes MM, Gazarini LC, Rodrigues ML (2001). Acclimation of Myrtus communis to contrasting Mediterranean light environments - effects on structure and chemical composition of foliage and plant water relations. Environmental and Experimental Botany 45: 165-178. - doi: 10.1016/ S0098-8472(01)00073-9

Meng F, Cao R, Yang D, Niklas KJ, Sun S (2014). Trade-offs between light interception and leaf water shedding: a comparaison of shade and sun-adapted species in a subtropical rainforest. Oecologia 174:13-22. - doi: 10.1007/s0044 2-013-2746-0

Mishra KB, Iannacone R, Petrozza A, Mishra Anamika, Armentano N, La Vecchia G, Trtilek M, Cellini F, Nedbal L (2012). Engineered drought tolerance in tomato plants is reflected in chlorophyll fluorescence emission. Plant Science 182: 79-86. - doi: 10.1016/j.plantsci.2011.03 022

Müller P, Xiao-Ping L, Niyogi K (2001). Nonphotochemical quenching. A response to excess light energy. Plant Physiology 125:1558-1566. doi: $10.1104 / p p .125 .4 .1558$

Ort DR (2001). When there is too much light. Plant Physiology 25: 29-32. - doi: 10.1104/pp. 125.1.29

Priault P, Fresneau C, Noctor G, De Paepe R, Cornic G, Streb P (2006). The mitochondrial CMSII mutation of Nicotiana sylvestris impairs adjustment of photosynthetic carbon assimilation to higher growth irradiance. Journal of Experimental Botany 57: 2075-2085. - doi: 10.1093/jxb/ erj161

Price GD, von Caemmerer S, Evans JR, Siebke K, Anderson JM, Badger MR (1998). Photosynthe- sis is strongly reduced by antisense suppression of chloroplastic cytochrome $b f$ complex in transgenic tobacco. Australian Journal of Plant Physiology 25: 445-452. - doi: 10.1071/PP97164

Ramirez-Valiente JA, Sanchez-Gomez D, Aranda I, Valladarres F (2010). Phenotypic plasticity and local adaptation in leaf ecophysiological traits of 13 contrasting cork oak populations under different water availabilities. Tree Physiology 30: 618-627. - doi: 10.1093/treephys/tpq013

Rozendal DMA, Hurtado VH, Poorter L (2006). Plasticity in leaf traits of 38 tropical species in response to light; relationships with light demand and adult stature. Functional Ecology 20: 207-216. - doi: 10.1111/j.1365-2435.2006.011 05.x

Rzigui T, De Paepe R, Cornic G, Streb P (2013). In the mitochondrial CMSII mutant of Nicotiana sylvestris photosynthetic activity remains higher than in the WT under persisting mild water stress. Plant Science 205-206: 20-28. - doi: 10.1016/j.plantsci.2013.01.010

Sack L, Holbrook NM (2006). Leaf hydraulics. Annual Review of Plant Biology 57: 361-381. doi: 10.1146/annurev.arplant.56.032604.144141 Sanchez-Gomez D, Valladares F, Zavala M (2006). Functional traits and plasticity in response to light in seedlings of four Iberian forest tree species. Tree Physiology 26: 1425-1433. - doi: 10.1093/treephys/26.11.1425

Schluter U, Muschak M, Berger D, Thomas A (2003). Photosynthetic performance of an Arabidopsis mutant with elevated stomatal density (sdd1-1) under different light regimes. Journal of Experimental Botany 54:867-874. - doi: 10.109 3/jxb/erg087

Staudt M, Ennajah A, Mouillot F, Joffre R (2008). Do volatile organic compound emissions of $\mathrm{Tu}$ nisian cork oak populations originating from contrasting climatic conditions differ in their responses to summer drought? Canadian Journal of Forest Research 38: 2965-2975. - doi: 10.1139/
X08-134

Sugiura D, Tateno M (2014). Effect of the experimental alteration of fine roots on stomatal conductance and photosynthesis: case study of devil maple (Acer diabolicum) in a cool temperate region. Environmental and Experimental Botany 100: 105-113. - doi: 10.1016/j.envexpbot.2013. 12.020

Sultan SE (2003). Phenotypic plasticity in plants: a case study in ecological developmet. Evolution and Development 5: 25-33. - doi: 10.1046/j. 1525-142X.2003.03005.x

Valladares F, Martinez-Ferri E, Blaguer L, PerezCorna E, Manrique E (2000). Low leaf-level response to light and nutrients in Mediterranean evergreen oaks: a conservative resource-use strategy? New Phytologist 148: 79-91. - doi: 10.1046/j.1469-8137.2000.00737.x

Valladares F, Chico JM, Aranda L, Blaguer P, Dizengremel E, Manrique E, Dreyer E (2002). The greater high-light seedling tolerance of Quercus robur over Fagus sylvatica is linked to a greater physiological plasticity. Trees 16: 395403. [online] URL: http://link.springer.com/article/10.1007/s00468-002-0184-4

Valladares F, Dobarro I, Sanchez-Gomez D, Pearcy RW (2004). Photoinhibiton and drought in Mediterranean woody saplings: scaling effects and interactions in sun and shade phenotypes. Journal of Experimental Botany 56: 483-494. doi: $10.1093 /$ jxb/eri037

Valladares F, Arrieta S, Aranda I, Lorenzo D, Sanchez-Gomez D, Tena D, Suarez F, Pardos JA (2005). Shade tolerance, photoinhibition sensitivity and phenotypic plasticity of Ilex aquifolium in continental Mediterranean sites. Tree Physiology 25: 1041-1052. - doi: 10.1093/treephys/25.8.1041

Walters RG (2005). Towards and understanding of photosynthetic acclimation. Journal of Experimental Botany 56: 435-447. - doi: 10.1093/jxb/ eri060 